\title{
Spontaneously acquired fistula from the right coronary artery to the right ventricular cavity
}

\author{
S G Ray, M D Cowan, J A Kennedy
}

Departments of Cardiology and Radiology, Western Infirmary, Glasgow S G Ray M D Cowan J A Kennedy Correspondence to Dr S G Ray, Department of Cardiology, Cardiothoracic Centre, Broadgreen Hospital, Thomas Drive, Liverpool L14 3PE.

\begin{abstract}
A 47 year old man developed a fistula from the right ventricular branch of the right coronary artery to the right ventricular cavity in association with distal occlusion of the main trunk of the right coronary artery. There was no clinical or electrocardiographic evidence of acute myocardial infarction.
\end{abstract}

The development of coronary artery fistulas after myocardial infarction has been reported but is very rare. ${ }^{12}$ We report a case of an acquired right coronary artery fistula to the

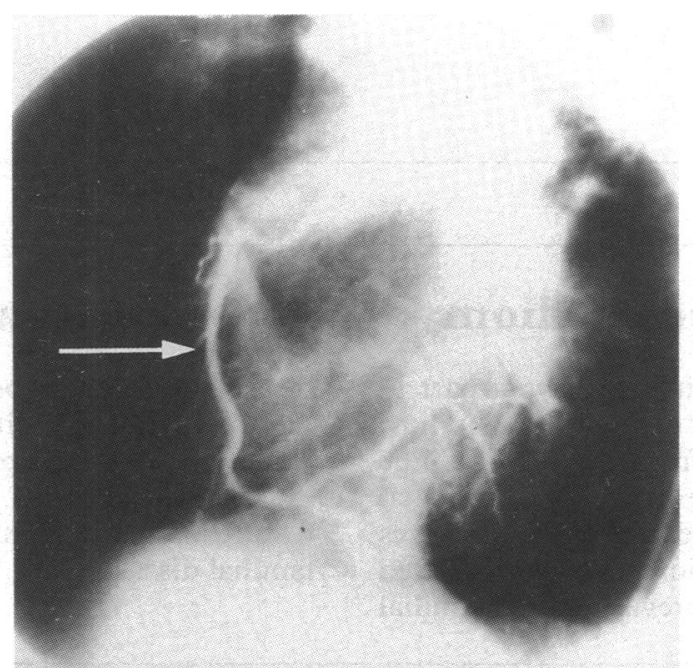

Figure $160^{\circ}$ Left anterior oblique view of the right coronary artery in 1982.
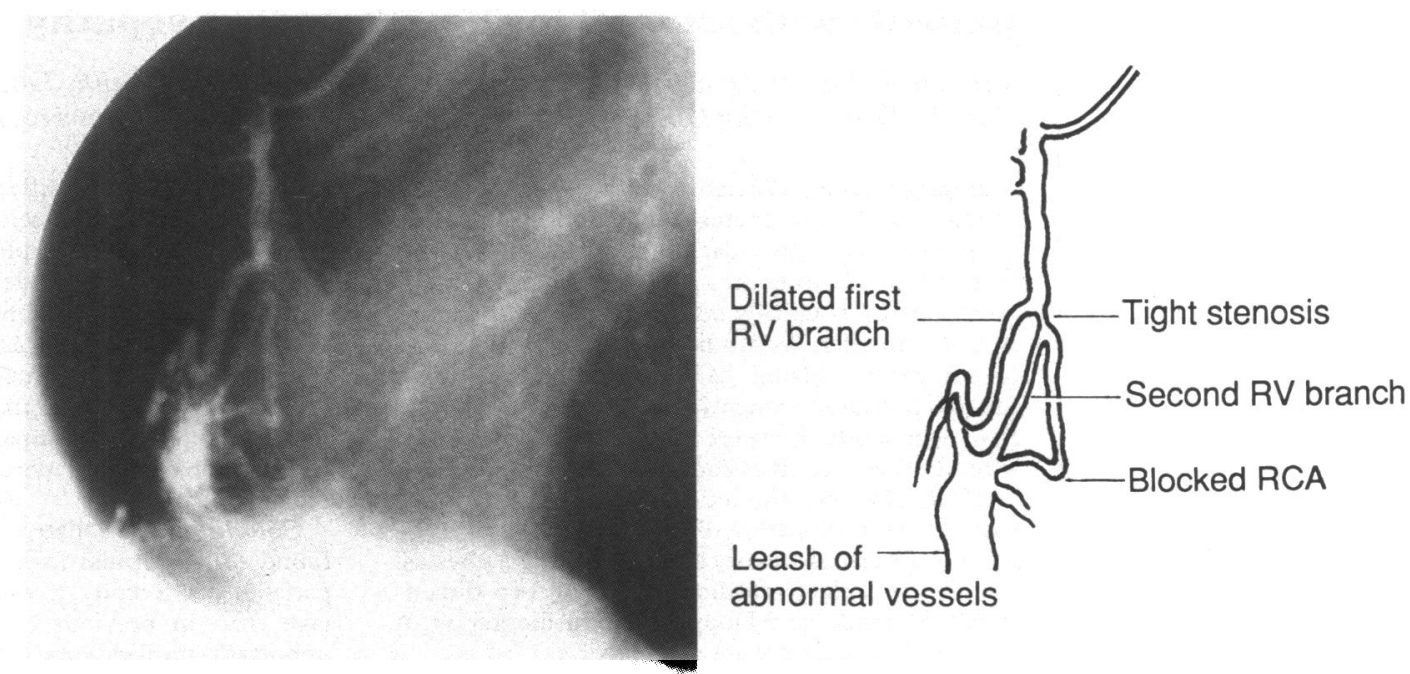

abnormal vessels

right ventricle in association with arterial occlusion but without electrocardiographic evidence or a clinical diagnosis of myocardial infarction.

\section{Case report}

A 42 year old white man presented in November 1982 with an anterior myocardial infarction. Left ventricular angiography in the convalescent period showed a small anteroapical aneurysm but good global ventricular function. At coronary angiography there was a $50 \%$ diameter stenosis in the left anterior descending artery and minor atheromatous change in the right coronary artery (fig 1). Medical treatment was continued and he made an uneventful recovery and subsequently did not attend for follow up examination.

In May 1987 he was readmitted with prolonged ischaemic chest pain brought on by exercise. There was no evidence of myocardial infarction and his resting electrocardiogram was unchanged from that in 1982. Exercise testing showed considerable inferior ischaemia, and he underwent repeat cardiac catheterisation in April 1988. On this occasion there was considerable hypokinesia of the inferior and posterior portions of the left ventricle. There was a $70 \%$ diameter stenosis of the left anterior descending artery and a $50 \%$ diameter stenosis of the obtuse marginal branch of the circumflex artery. The previously dominant right coronary artery was occluded (fig 2) and filled to the crux from the left. There was a tight stenosis of the right

Figure $260^{\circ}$ Left anterior oblique view of the right coronary artery in 1988 showing the occluded main trunk of the artery, the dilated first right ventricular $(R V)$ branch and the abnormal leash of vessels draining directly into the right ventricular cavity. RCA, right coronary artery. 
coronary artery just distal to its first right ventricular branch, which was considerably dilated and (together with several smaller vessels) was feeding an abnormal leash of vessels draining directly into the right ventricular cavity.

He underwent coronary artery bypass grafting. At operation there was no suggestion of a tumour and the inferior surface of the heart was free of important scarring, which accorded with the lack of electrocardiographic or clinical evidence of a second infarct. The dilated first right ventricular branch of the right coronary artery was identified and tied off distally. No other abnormal vessels could be visualised.

\section{Discussion}

We are aware of one report of an angiography documented acquired coronary artery fistula after myocardial infarction in which a fistula developed from the diagonal branch of the left anterior descending artery and communicated with the left ventricular cavity. ${ }^{1}$ At rest our patient had considerable wall motion abnor- mality in the territory of the right coronary artery but no history or electrocardiographic changes suggestive of infarction. Chronic ischaemia produced by progressive occlusion of the right coronary artery could have caused the wall motion abnormality while at the same time acting as the stimulus for the development of collateral vessels from the first right ventricular branch. Aberrant development of collateral vessels then led to fistula formation. Myocardial ischaemia in patients with congenital and acquired coronary artery fistulas has been attributed to coronary steal. ${ }^{13}$ The development of the fistula in our patient could have coincided with the worsening of ischaemia and his readmission in 1987.

We thank Mr M P G Jamieson for permission to report the surgical findings.

1 Yu R, Sharma B, Franciosa JA. Acquired coronary artery fistula to the left ventricle after acute myocardial infarction. Am J Cardiol 1986;58:557-8.

2 Ryan C, Gertz EW. Fistula from coronary arteries to left ventricle after myocardial infarction. Br Heart J 1977 ; 39:1147-9.

3 Wilde P, Watt I. Congenital coronary artery fistulae: six new cases with a collective review. Clin Radiol 1980;31:301-11.

\section{ABSTRACTS IN CARDIOLOGY}

\section{Familial dilated cardiomyopathy-not so rare}

We all know that inheritance plays a part in dilated cardiomyopathy: the question is how big a part. This study from the Mayo Clinic suggests that one in five patients with dilated cardiomyopathy will have one or more relatives who fulfil the diagnostic criteria for dilated cardiomyopathy. The prevalence of familial disease is likely to be greater than the $20 \%$ reported, as an additional 28 patients $(9 \%)$ from 22 families were considered to be of indeterminate status. There are no clinical features that distinguish familial from nonfamilial disease.

WILLIAM J McKENNA

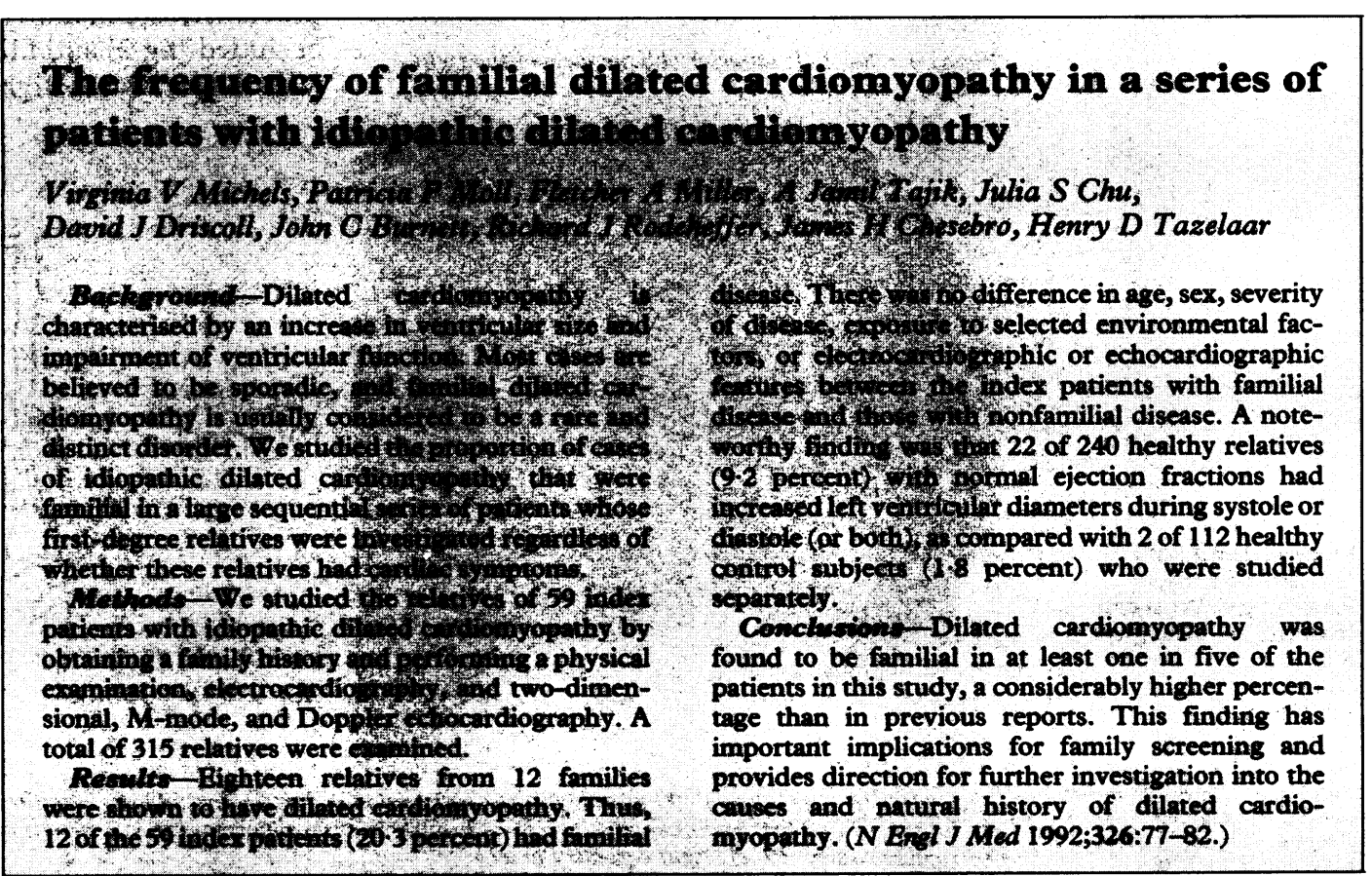

